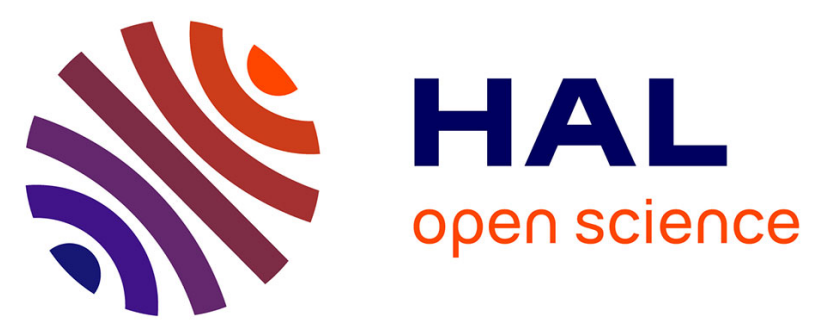

\title{
PLM Standards Modelling for Enterprise Interoperability: A Manufacturing Case Study for ERP and MES Systems Integration Based on ISA-95
}

\author{
Emna Moones, Thomas Vosgien, Lyes Kermad, El Mouloudi Dafaoui, \\ Abderrahman El Mhamedi, Nicolas Figay
}

\section{To cite this version:}

Emna Moones, Thomas Vosgien, Lyes Kermad, El Mouloudi Dafaoui, Abderrahman El Mhamedi, et al.. PLM Standards Modelling for Enterprise Interoperability: A Manufacturing Case Study for ERP and MES Systems Integration Based on ISA-95. 6th International IFIP Working Conference on Enterprise Interoperability (IWEI), May 2015, Nîmes, France. pp.157-170, 10.1007/978-3-662-471579_14. hal-01438399

\author{
HAL Id: hal-01438399 \\ https://hal.inria.fr/hal-01438399
}

Submitted on 17 Jan 2017

HAL is a multi-disciplinary open access archive for the deposit and dissemination of scientific research documents, whether they are published or not. The documents may come from teaching and research institutions in France or abroad, or from public or private research centers.
L'archive ouverte pluridisciplinaire HAL, est destinée au dépôt et à la diffusion de documents scientifiques de niveau recherche, publiés ou non, émanant des établissements d'enseignement et de recherche français ou étrangers, des laboratoires publics ou privés. 


\title{
PLM standards modelling for enterprise interoperability: A manufacturing case study for ERP and MES systems integration based on ISA-95
}

\author{
Emna Moones ${ }^{1,2}$, Thomas Vosgien ${ }^{1}$, Lyes Kermad ${ }^{2}$, El Mouloudi Dafaoui², \\ Abderrahman El Mhamedi ${ }^{2}$, Nicolas Figay ${ }^{3}$ \\ ${ }^{1}$ Technological Research Institute SystemX, Palaiseau, France \\ \{emna.moones, thomas.vosgien\}@irt-systemx.fr \\ 2 University Paris8, 140 rue Nouvelle France, 93100 Montreuil, France \\ \{1.kermad, e.dafaoui, a.elmhamedi\}@iut.univ-paris8.fr \\ 3 Airbus Group Innovations, 12 rue Pasteur 92150 Suresnes, France \\ \{nicolas.figay\}@airbus.com
}

\begin{abstract}
Today Enterprise Interoperability is considered as a key factor of successful collaboration. It was identified as a critical need that has to be taken into account all along the lifecycle of a manufactured product. To deal with this problem and to reduce complexity of the different systems of interest used when different companies have to collaborate together, Enterprise Architecture (EA) and Enterprise Modelling (EM) are considered as solutions to facilitate Enterprise Interoperability. Dealing with interoperability issues in the context of Product Lifecycle Management (PLM), we have to mention the importance of product data and process standards implementation as interoperability enablers. In order to address the complexity of PLM standards, we propose to apply a model-driven methodology for modelling these standards and the related collaboration scenarios. This approach intends to make standards more comprehensive and to better manage standards evolutions, but also to instantiate and re-use these "generic" standards models to specify specific business collaboration scenarios. This proposal aims also to facilitate the exchange, testing and simulation of standards implementations. In this paper, the focus is on the ISA 95 standard for manufacturing-PLM integration, with an exchange scenario between Enterprise Resource Planning (ERP) and Manufacturing Execution System (MES) based on ISA 95 standard.
\end{abstract}

Keywords: Enterprise Architecture, Enterprise Interoperability, Manufacturing PLM standards, ERP/MES, ISA-95.

\section{Introduction}

Nowadays in order to remain competitive within a global economic context where the complexity of products is still increasing, enterprises have been developing new strategic approaches such as the PLM approach. PLM is defined, by CIMDATA [1], as a strategic approach aiming at setting-up appropriate processes related to production and consumption of product data, all along the different product lifecycle phases and across the whole supply chain. Along the product lifecycle phases, enterprise business 
functions and processes are supported by different PLM solutions including the Information System (IS) such as Product Data Management (PDM) systems for design engineering activities and configuration management, ERP and MES for manufacturing, business planning and logistic operations. PLM solutions include PLM Hubs, such as BoostAerospace' ${ }^{1}$. In such a context, efficient, agile and interoperable IS and interfaces are required in order to ensure the continuity, consistency and integrity of the different /shared exchanged product and process data.

Governance of standards, as addressed by ASD $\mathrm{SSG}^{2}$, is facing difficulties when elected eBusinessPLM standards and associated PLM standardization enterprise policies have to be applied. New challenges related to factories and support taking advantage of emerging technologies are also to be considered in order to support competitiveness of enterprises. To deal with the context of PLM standards and their complexity, the Standard and Interoperability PLM $\left(\mathrm{SIP}^{3}\right)$ project was launched within the frame of the IRT-SystemX' $\mathrm{X}^{4}$. The adopted approach in this project is based on a federating framework for interoperability of technical enterprise applications [2]. While different projects such as INTEROP[3] and ATHENA[4] has addressed the interoperability of enterprise applications relying on a common Application Interoperability Framework (AIF), our approach also relies on a federative interoperability framework defined by [2]. This framework defines a pragmatic methodology for preparing and building operational interoperability (as defined by System Of System Interoperability (SOSI) [5]) at an acceptable price for Dynamic Manufacturing Network (DMN) [6][7].

SIP project aims at extending the federative network by addressing new identified brakes, in particular the importance to be able to assess standards and their implementations to support DMN collaboration. It introduces and analyses the ArchiMate standard as a way to properly rely on enterprise modelling as a key enabler for dealing with the specification and simulation of DMN business collaboration scenarios in order to better prepare enterprise interoperability. The SIP methodology relies on the use of a test bed allowing execution and simulation of DMN models. The testbed is built on top of a collaborative platform constituting a hub for interconnection of technical enterprise applications. It integrates enterprise collaboration technical solutions (enterprise portal, enterprise service bus, enterprise workflow system, etc.) using appropriate open standards. It also integrates PLM standard-based technical solutions for product data exchange and sharing, with appropriate applicative services. On such a platform, the test bed introduces testing specification, development and management of capabilities applying Model-Based System Engineering (MBSE).

The issue addressed in this paper concerns the reasons for modelling PLM standards and the way to model these standards so that we can re-use these models to specify and simulate standards-based collaboration scenarios. The idea is also to investigate the use of such approaches to specify testing procedures and related validation properties for assessing standards implementations.

\footnotetext{
${ }^{1} \mathrm{http}: / /$ www.boostaerospace.com/

${ }^{2} \mathrm{http}: / /$ www.asd-ssg.org/

${ }^{3} \mathrm{http}: / /$ www.irt-systemx.fr/project/sip/

${ }^{4}$ http://www.irt-systemx.fr/
} 
In this context, we propose to apply and extend the SIP methodology on business manufacturing data exchange business cases and particularly for enabling efficient data integration between ERP and MES systems.

Section 2 hence provides a state of the art about enterprise modelling approaches languages and tools. Based on the literature, it also explains how the interoperability of business processes could be achieved by using models. A second sub-section of the state of the art present the used ISA-95 standard for ERP and MES systems integration. Section 3 introduce our proposal and illustrates how we managed to model different aspects of the ISA-95 standard. Finally we also introduce in this section the DEKENZ case study in which we specify a data exchange and integration scenario between an ERP system and different MES systems re-using and instantiating the ISA 95 standard model. Conclusions and future work are presented in section 4.

\section{State of the art}

Interoperability is the ability of several systems, whether identical or radically different, to communicate without ambiguity and operate together [8]. Considering a PLM strategy in a DMN context, standardized interfaces between processes and supporting resources (human and ICT resources) are required in order to ensure the continuity, consistency and integrity of the different shared/exchanged product and process data all along the product lifecycle and across business domains. As a result PLM Standards have largely been identified in the literature as interoperability enablers [9][2]. A PLM standard is not only a technical solution for product data exchange but also a strategic answer that has to consider:

- The strategic business motivations of the organizations involved in the DMN;

- The business engineering needs of the addressed collaboration processes;

- The human and applicative resources supporting these business processes that intend to become interoperable;

- $\quad$ The ICT systems in which standards will be implemented;

- The technological solutions for using standardized data format;

- The infrastructures permitting to organizations to connect their applications and to share/exchange their standardized process and product data.

Therefore, PLM standards are very complex and hence difficult and costly to implement. One way to address this complexity is to model these standards and related business cases using Enterprise Architecture Modelling considering these different dimensions. One of the goal of this paper is to study these frameworks to use and/or to extend them in view to specify and model standards-based business collaboration scenarios. The finality is then to be able to simulate these scenarios to prepare and build the interoperability of future DMNs. 


\subsection{Enterprise architecture modelling for PLM interoperability}

An enterprise architecture (EA) description is usually very complex, because it comprises a large set of components and relationships between them. EA is a coherent whole of principles, methods and models that are used in the design and realisation of the enterprise's organisational structure, business processes, information systems, and infrastructure [10]. However, in practice, these domains are not approached in an integrated way. Every domain speaks its own language, draws its own models, and uses its own techniques and tools. According to [11], architecture allows managing complexity and risks due to various factors such as technology, size, interface, context and stakeholders. Therefore, it is important that EA can be represented with relevant information and at the appropriate level of detail for individual stakeholders. More generally, EA must show properties that can be verified with respect to user needs (e.g. open or closed architecture, interoperable or not, centralized or decentralized, etc.)[11]. It must be simple so that business people can easily understand, check, analyse, discuss in a 'language' shared at the corporate level. According to [11] enterprise architecture models describe the EA from various viewpoints to allow specifying and implementing the systems. For this purpose, numerous approaches, methods and frameworks (e.g. Zachman[12], CIMOSA[13], TOGAF[14]) have been developed to consider these different viewpoints related with different stakeholders.

In literature, it is possible to distinguish between simple methods of representation (SADT, IDEFx, GRAI, IEM, etc.) and reference architectures (CIMOSA, ARIS, PERA, GERAM, GIM, etc.). These latter offer a set of structured methods with a methodology to be followed to build the model. But, these methods are, in most cases, difficult to implement. In other cases, we note the existence, according to the viewpoints, of different languages that must be studied and mastered. Moreover, the models defined according to these different viewpoints are related and when a change occurs on one model, the consistency of the impacted related models must be insured. However, due to the heterogeneity of the methods and techniques used to document the architectures, it is very difficult to determine how the different domains are interrelated. Still, it is clear that there are strong dependencies between the domains[10]. Also, it should be possible to visualise models in a different way, tailored towards specific stakeholders with specific information requirements.

For all these reasons, we propose a modelling methodology based on the TOGAF framework and the ArchiMate ${ }^{5}$ enterprise architecture language due to its ability to model an enterprise system interrelating domain specific architectures and crossdomain relationships. The ArchiMate language divides the enterprise architecture into a business, applicative and technological layer. In each layer, three aspects are considered: active elements that exhibit behaviour (e.g. Process and Function), an internal structure and elements that define use or communicate information. The use of ArchiMate language in our methodology allows us to model different system architectures. First it is used to model the standard architecture itself and related test procedures. Secondly it used to specify business collaboration processes and their related applicative and technological chains. Finally it also used to specify the as-is and

\footnotetext{
${ }^{5} \mathrm{http} / / /$ www.opengroup.org/subjectareas/enterprise/archimate
} 
to-be applicative and technological integration platforms as well as the different SIP "test beds".

\subsection{ISA-95 a standard for ERP and MES systems integration}

While addressing the role of PLM standards it is important to distinguish the different types of standards included in the scope of a PLM approach. Moreover, the interoperability across system information might be addressed distinguishing the product or system taken into account. The global and main role of information exchange standards is to reduce the number of inter-change protocols from the unmanageable multitude of one-to-one interchanges to a finite number of distinct and meaningful compositions of coherent information across time, space and multiple disciplines [9].

In our context, we are particularly interested by the ISA 95 standard developed to address interoperability issues between ERP systems and MES. ISA-95 is defined according to [15] as the international standard for the integration of enterprise and control systems. It consists of models and terminology that can be used to determine which information has to be exchanged between systems for sales, finance, logistics, production, maintenance and quality. Four functional levels are defined by ISA 95 standard. Levels 0,1 and 2 are the levels of process control. Their objective is the control of equipment, in order to execute production processes that end in one or more products. Level 3 could be called the level of MES activities, it consists of several activities that must be executed to prepare, monitor and complete the production process that is executed at level 0,1 and 2. The highest level (level 4) could be called the level of enterprise, including ERP systems and PDM Systems. At this level financial and logistic activities are executed in order to produce the product configuration ordered by the client. Next section, which introduces the proposed methodology, also provides extracts of the ISA-95 standard modelled with the use of the ArchiMate language.

\section{Proposed methodology and case study}

In this section, the SIP methodology and the use of ISA-95 standard are introduced. The SIP methodological modelling framework is presented and its application is illustrated first by modelling the ISA-95 standard and secondly specifying/modelling an information exchange scenario between ERP and MES based on ISA-95.

\subsection{SIP methodology}

SIP methodology aims at validating a set of coherent PLM standards and their implementations. The first objective is to develop an innovative interoperability framework (shown in figure 1) in order to provide a model-driven methodology for the development of a PLM standards assessment test bed which will be implemented as a service. 


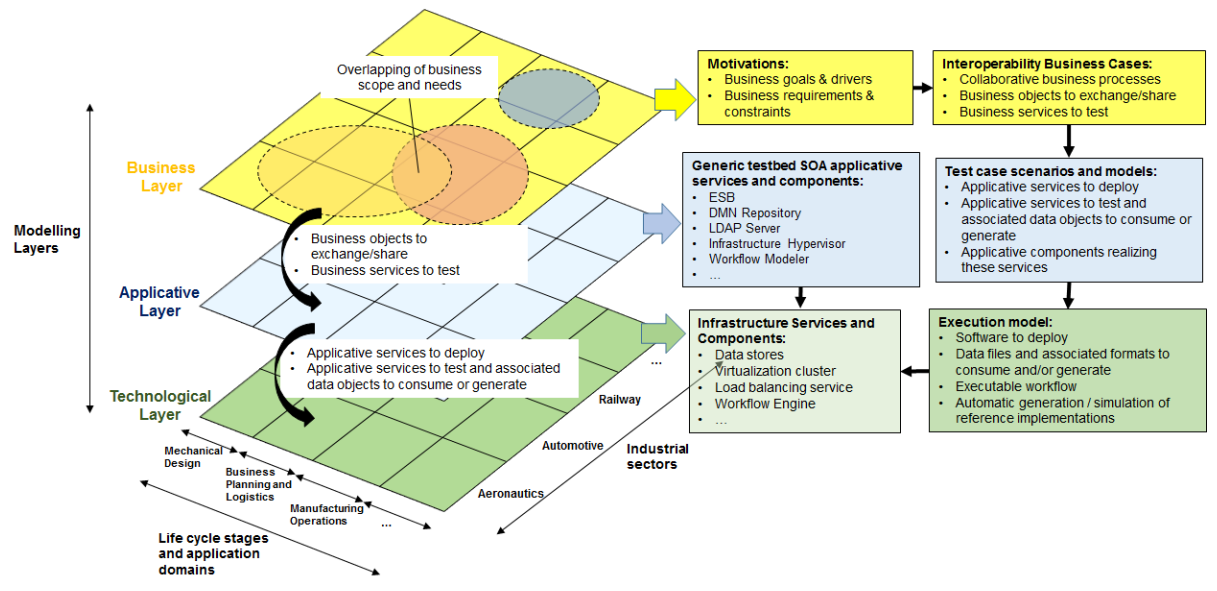

Fig 1. SIP methodological modelling framework

First of all, we have to model the DMN and the strategic motivations of the different stakeholders. Still on the business layer, the second step consists in collecting and modelling interoperability business cases and related exchange and test scenarios. The supporting applicative chains that supports these scenarios are then specified at the applicative layer. Finally the execution model to simulate is modelled to prepare the appropriate test bed infrastructure configuration. In parallel the framework also provides architectural viewpoints to specify the generic and specific applicative and technological components of the test bed. This figure is not fully representative of the SIP framework since it does not include the step consisting in modelling PLM standards. However next section illustrates the way of performing this step using ArchiMate language to model ISA-95.

Moreover, using models instead of text documents enables first to constitute a knowledge base of PLM standards models. These models should include a set of reusable standards-based collaboration templates of the different functional modules of the standard. A PLM standard can specify the supported business processes, as well as the product and process data models to implement in ICT systems., we will have a multi-layer view with the modelling of the processes (organizational layer), the data models (applicative layer) and specifying the software solutions (technological layer).. Cross this way, modelling the standard allow us to show the link between the different layers, the information flow between each layer. Also with this method, we can put in place the exchange protocols described in the documentation of the standard, we can define a validation properties for the implementation of the standard and we will construct a templates of the standard that can be exploited in various specific implementation scenarios. The test and the validation will be based on the generation of recommended practices, test processes with the integration of real applications and single test, all this to generate solutions which implement standards and which can be easily integrated [6][7]. 


\subsection{The ISA-95 standard}

In this part we will introduce the structure of the ISA-95 standard and the application of the SIP methodology for modelling the standard with ArchiMate.

\subsubsection{Content and structure of the standard}

The ISA-95 standard is structured in five parts. The first part presents the models and terminologies for analysing and exchanging information between level 4 (ERP) and level3 (MES). The second part shows the data models in order to standardize the structure and the information flows defined by part 1 . In part 3 ISA-95 defines the four operations group that it covers in manufacturing activities which are: Production, Maintenance, Quality and Inventory operations. Part 4 specifies the informational flow between the four types of operations defined in part 3. Finally part 5 standardizes the implementation format and transactions data messages which transit between ERP systems and MES systems.

\subsubsection{Modelling ISA-95 with ArchiMate}

Based on the ISA-95 specifications[16], we have modelled a set of reusable ISA95-based collaboration templates of the different functional modules of the standard. This templates intend to be re-used in specific business collaboration scenarios requiring a strong ERP-MES integration. Figure 2 represents the functional model of ISA-95 gathering the several functions covered by the MES and the ERP and the information flow between these business functions. Indeed the functions supported by the ERP systems are: Order processing, Product cost accounting, Product shipping admin, Procurement, Research development and engineering. The MES supports the following functions: Production control, Quality assurance, Maintenance management. The rest of the functions which are Production scheduling, Product inventory control, Material and energy control are supported by both the ERP and the MES systems. Our ISA-95 model also includes several levels of abstraction providing more detailed views of these functions which are not shown in this paper. These standardized business functions will be re-used in the frame of case study described in section 4 . 


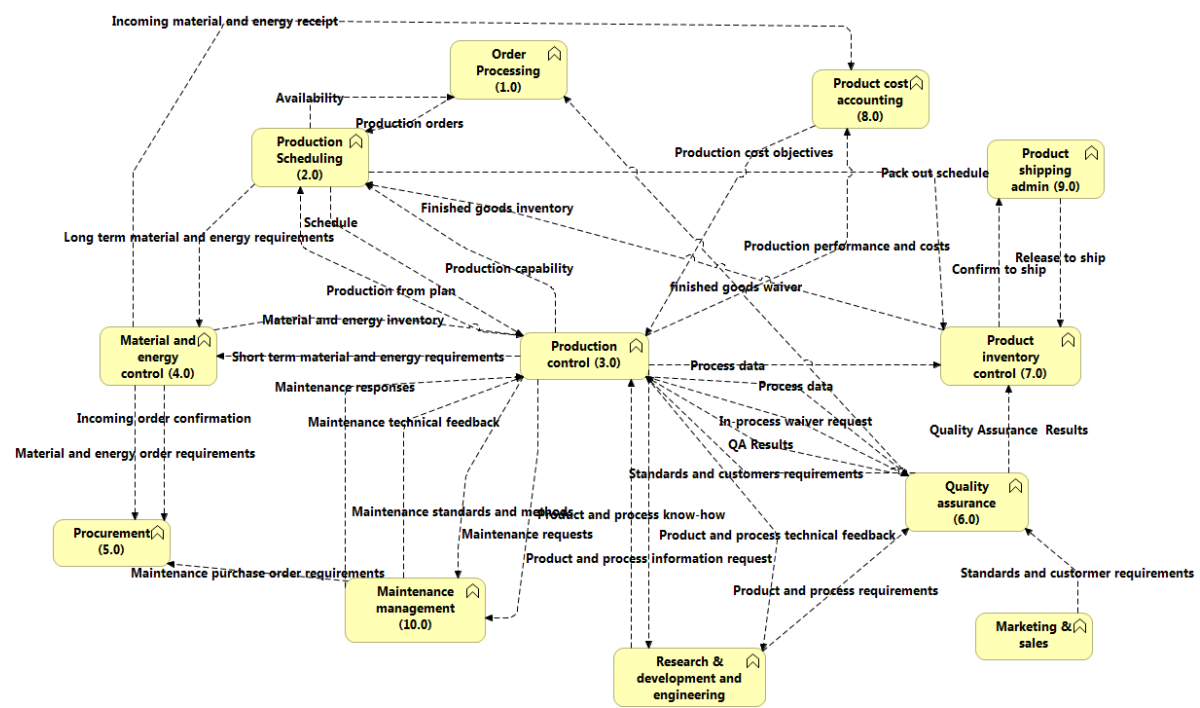

Fig. 2. Functional model of ISA-95in ArchiMate

In Figure 3 the business functions of figure 2 have been categorized according to their belonging to the higher level business functions "Business Planning \& Logistics" and "Manufacturing operations management" corresponding respectively to level 4 (supported by ERP and PDM system) and level 3 (supported by MES) of ISA-95 mentioned in section 2.2. For instance, the functional level 3 is sub-divided in four subfunctions: Production, Maintenance, Quality and Inventory operations management. Different levels of abstraction appear in this diagram since all these sub-functions are also detailed with activities sequencing diagrams as defined in the ISA-95 standard.

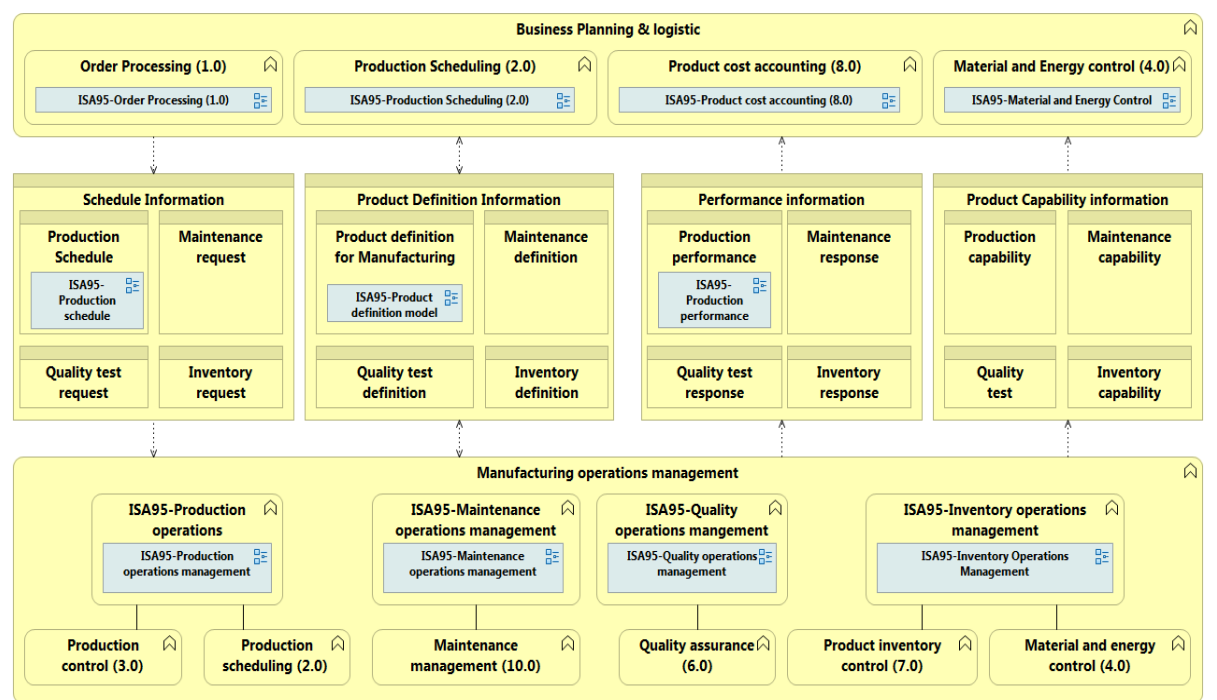

Fig. 3. Generic ISA-95-based ERP/MES business functions and data flows 
Figure 3 also details the standardized data flows between these business functions. According to ISA-95 documentation, four categories of information are exchanged between the business and the manufacturing layers: schedule information, product definition information, performance information and product capability information. Each of these categories is also sub-divided into four sub-categories of data flows corresponding to the information consumed or generated by the level 3 sub-functions. For instance, the schedule information category includes production schedules, maintenance requests, quality test requests and inventory requests. Each of these business objects are also detailed at the applicative layer to represent the various standardized data models defined by ISA-95. Figure 4 shows the product definition model as defined by ISA-95 in part 2 and permitting to define the shared information between product production rules, bill of materials and bill of resources. One limit of ArchiMate we had to deal with when capturing the information model of ISA95, which is formalized in UML, is the missing ability of the language to capture reflexive relationship.

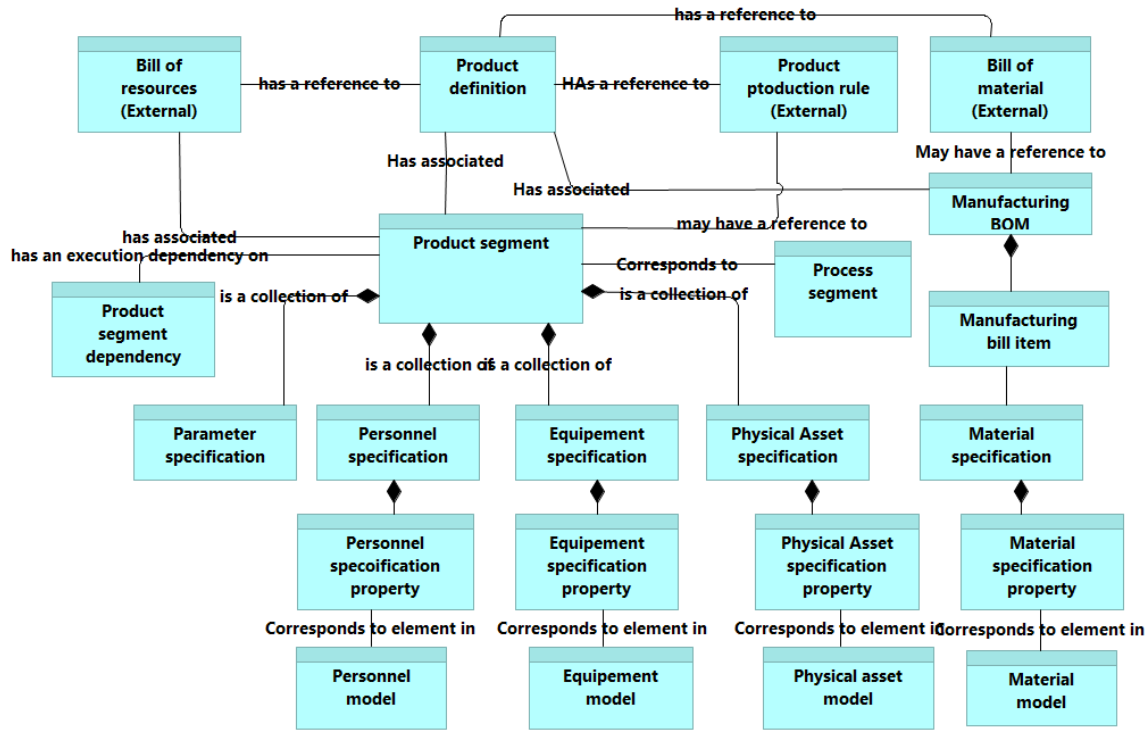

Fig. 4. ISA-95 Product definition object model in ArchiMate

To exchange these data in standardized way, ISA-95 also defines the way to structure the transaction messages which transit between business and manufacturing layers. The different kind of ISA-95 transactions data set are represented in figure 5 where the content, structure and implementation ISA-95 format are defined. An ISA-95 transaction data set is first composed of an "application identification area" which includes information about the origin of the message and where it will be transmitted. It includes a "data area" which includes a "verb area" for sending a demand (get, change, cancel, etc.) or responding to a demand (show, confirm, respond, etc.) and the "noun area" specifying the kind of exchanged data objects (as defined in part 2 of ISA95). The "noun area" contains the standardized information models as defined in part 2 
and implemented in an ISA-95 compliant XML format: the Business To Manufacturing Mark-up Language (B2MML). The transaction message is based on three models, a pull model where a user of data requests the data from a provider of the data, a push model where a provider of data requests an action (processing, changing, or cancelling) on the data by another user and a publish model where the owner of data publishes it to users (subscribers) of the data.



Fig. 5. ISA-95 Transaction Data Set between ERP and MES model in ArchiMate

This section introduced some extracts of the ISA-95 ArchiMate model. This model includes reusable ISA95-based collaboration templates, such as the ones shown in Figure 3 . In the next section these templates are re-used to model and specify an interoperability business case study.

\subsection{Modelling and specifying ISA-95-based data exchange scenarios with ArchiMate}

DEKENZ $^{6}$ is a French company specialized in the development, the fabrication and the marketing of pens with the particularity that its labour is mainly ensured by students located in different universities in France. The objective of this concept was to provide to universities an operational training to the functioning of a company. The finished DEKENZ pen showed in figure 6 is a pen mainly composed of Aluminium. It is composed of a cap assembly (itself composed of cap, a cap stopper, a staple and an inner clip), a body assembly (itself composed of a body tube, a quill, a body stopper, a nose and a ring), a quill and a cartridge.

${ }^{6}$ DEKENZ website: $\underline{\text { http://pm.flamant.free.fr/dekenz/?p=accueil }}$ 


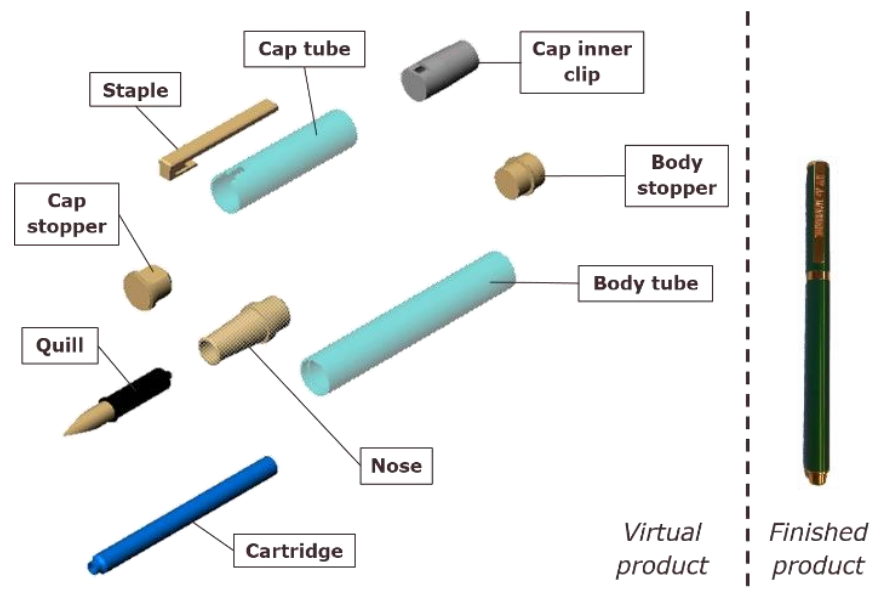

Fig. 6. DEKENZ product - Pen sub-components CAD models on the left and the finished product on the right

As shown on figure 7, the production of the cap and of the stopper as well as the integration of the cap and body assemblies is performed by students at "La Halle Technologique" of the IUT Montreuil ${ }^{7}$.

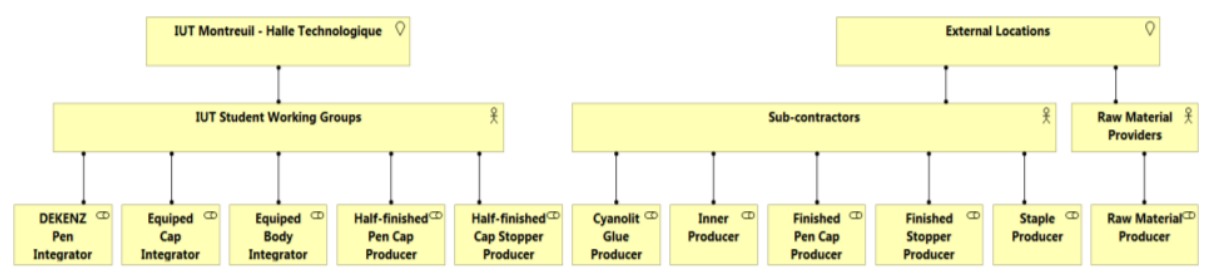

Fig. 7. DEKENZ case study - Map of actors and their roles

Figure 8 represents the business layer of the ERP-MES data integration scenario of the DEKENZ case study. The manufacturing process of this product is modelled on the bottom of the figure 8 . On top of the figure 8 are represented the business planning and logistics operations of the scenario; i.e. the pen production order creation, the production planning creation according to the Manufacturing Bill of Materials (MBOM) and to the inventory level of the pen components. In the middle of the figure 8 , the ISA-95 model shown in figure 3 is instantiated and re-used for this scenario permitting hence to specify the standardized data flows between the IUT ERP system and the IUT and the sub-contractors MES systems. For this paper we first focused on the exchange of MBOMs and production schedules/orders from the IUT ERP system and the MES systems but as well on the exchange of production performance and production capability information from the MES systems to the IUT ERP system.

${ }^{7}$ IUT Montreuil website : http://www.iut.univ-paris8.fr/ 




Fig. 8. DEKENZ Case study - ERP-MES data integration scenario 
Figure 9 below illustrates the To-Be applicative architecture supporting such a scenario as well as the data flows mentioned previously.

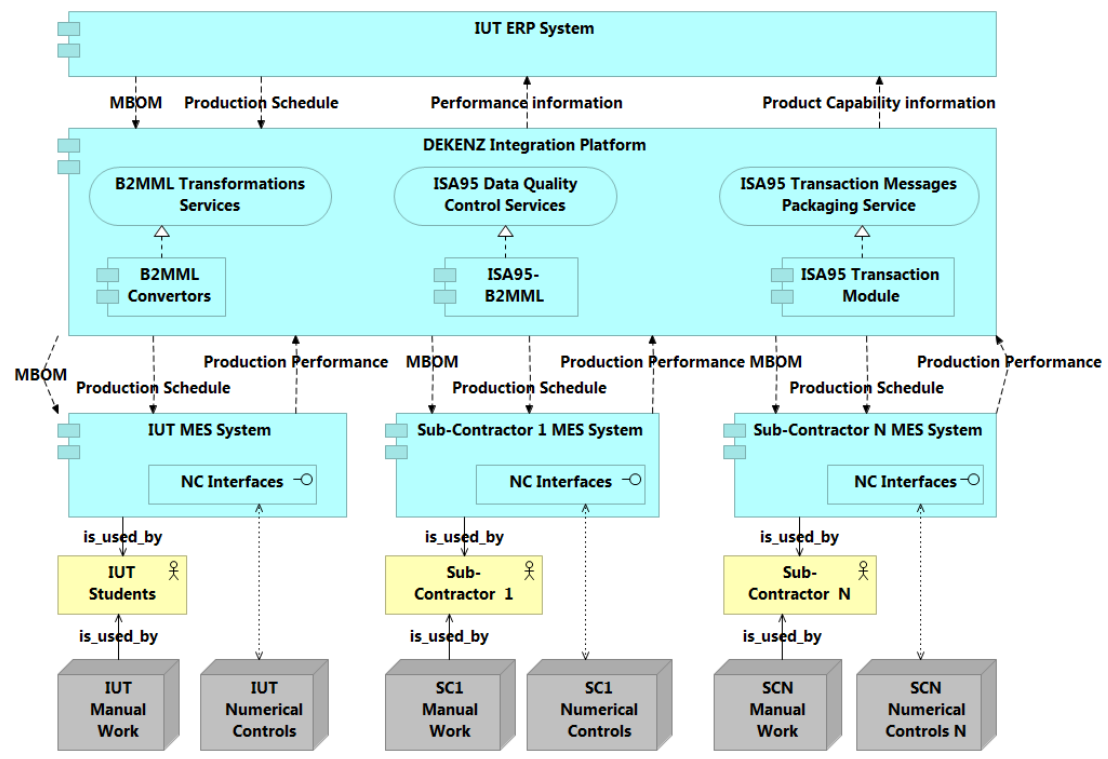

Fig. 9. To-Be applicative architecture for the DEKENZ ERP-MES integration scenario

One limit of ArchiMate we had to deal with is the missing modelling construct "asis" as we can find it in the Ontology Web Language, e.g. when willing to capture that a software system (ICT layer) is an instance of a software product (Business Layer) with an architecture (Applicative Layer) shared by all the instances of the product.

\section{Conclusion and future work}

This paper intends to demonstrate how the use of enterprise architecture modelling languages could contribute to better specify and prepare interoperability business cases. Extending the SIP methodology, this paper introduces a manufacturing case study for ERP and MES systems integration based on the ISA-95 standard. Some extract of the ISA-95 ArchiMate model are shown to illustrate the approach and the interest of reusing templates of these models to be re-used in different collaboration scenarios. Last section shows how the templates have been re-used and instantiated in the context of the DEKENZ ERP-MES integration scenario. The next steps will be:

- To instantiate the ISA-95 object models with the concrete DEKENZ case study data (MBOM, Production schedules, etc.).

- To create the related B2MML files to understand and analyse this implementation solution in view to develop the future B2MML converters and quality checkers.

- To create the related ISA-95 compliant transaction data messages.

- Define the quality control procedures to assess the conformity to the standard and to verify the content of the exchanged B2MML files. 
- $\quad$ Perform the mapping with the IUT ERP data model and the MES systems data models in order to further specify and/or develop the B2MML converters.

- $\quad$ Specify and/or develop the ISA-95 B2MML quality checkers.

- Address the limitations of the ArchiMate language by proposing some extensions to the community.

One of the target of this research work is to be able to simulate the collaboration on the SIP test bed and demonstrate the interest of using models to prepare, build, verify and validate enterprise interoperability with models.

Acknowledgments. This research work has been carried out under the leadership of the Technological Research Institute SystemX, and therefore granted with public funds within the scope of the French Program "Investissements d'avenir".

\section{References}

1. CIMDATA (2014) About PLM - CIMdata. https://www.cimdata.com/en/resources/about-plm.

2. Figay N (2009) Interoperability of Technical Enterprise Application. Université Claude Bernard Lyon 1

3. INTEROP (2007) European Commission: CORDIS. http://cordis.europa.eu/project/ren/71148_en.html.

4. ATHENA (2007) Interoperability Framework v2.0 - NEHTA. "Interoperability Framework. v2.0"

5. Morris E, Levine L, Meyers C, et al. (2004) System of Systems Interoperability (SOSI): final report (No. CMU/SEI-2004-TR-004). Carnegie-Mellon Univ Pittsburgh Pa Softw. Eng. Inst.

6. Figay N, Tchoffa D, Ghodous P, et al. (2014) Dynamic Manufacturing Network, PLM Hub and Business standards test bed.

7. Moones E, Figay N, Vosgien T, et al. (2014) Towards an extended interoperability systemic approach for Dynamic Manufacturing Networks : role and assessment of PLM standards.

8. Bourey JP, Grangel R, Ducq Y, et al. (2007) Report on Model Driven Interoperability.

9. Rachuri S, Subrahmanian E, Bouras A, et al. (2008) Information sharing and exchange in the context of product lifecycle management: Role of standards. CAD Comput Aided Des 40:789-800. Doi: 10.1016/j.cad.2007.06.012

10. Lankhorst MM (2004) Enterprise architecture modelling - The issue of integration. Adv Eng Informatics 18:205-216. Doi: 10.1016/j.aei.2005.01.005

11. Chen D, Doumeingts G, Vernadat F (2008) Architectures for enterprise integration and interoperability: Past, present and future. Comput Ind 59:647-659. Doi: 10.1016/j.compind.2007.12.016

12. Zachman J a (2003) The Zachman Framework For Enterprise Architecture, Primer for Enterprise Engineering and Manufacturing. CA Mag 128:15. Doi: 10.1109/CSIE.2009.478

13. Kosanke K, Vernadat F, Zelm M (1999) CIMOSA: Enterprise engineering and integration. Comput Ind 40:83-87. Doi: 10.1016/S0166-3615(99)00016-0

14. TOGAF® Version 9.1. http://www.opengroup.org/togaf/. Accessed 11 Feb 2015

15. Harjunkoski I, Bauer R (2014) Sharing data for production scheduling using the ISA-95 standard. 2:1-15. Doi: 10.3389/fenrg.2014.00044

16. ISA95, Enterprise-Control System Integration - ISA. https://www.isa.org/isa95/. Accessed $11 \mathrm{Feb} 2015$ 